九州大学学術情報リポジトリ

Kyushu University Institutional Repository

\title{
Studies of the Relationship Between Sound Absorption Coefficient and Air Permeability of Wood
}

KANG, Chun-Won

Department of Housing Environmental Design, and Research Institute of Human Ecology, College of Human Ecology, Jeonbuk National University

JANG, Eun-Suk

Department of Housing Environmental Design, and Research Institute of Human Ecology, College of Human Ecology, Jeonbuk National University

JANG, Sang-Sik

Department of Forest Products, College of Agriculture \& Life Sciences, Chungnam National University

\section{HASEGAWA, Masumi}

Laboratory of Wood Science, Department of Forest and Forest Product Science, Faculty of Agriculture, Kyushu University

他

https://doi.org/10.5109/4103900

出版情報: 九州大学大学院農学研究院紀要. 65 (2)，pp.351-355，2020-09. Faculty of Agriculture， Kyushu University

バージョン：

権利関係 : 


\title{
Studies of the Relationship Between Sound Absorption Coefficient and Air Permeability of Wood
}

\author{
Chun-Won KANG ${ }^{1}$, Eun-Suk JANG ${ }^{1}$, Sang-Sik JANG*², Masumi HASEGAWA ${ }^{3}$ and Jnuji MATSUMURA ${ }^{3}$ \\ Laboratory of Wood Science, Department of Forest and Forest Product Science, \\ Faculty of Agriculture, Kyushu University, Fukuoka 812-8581, Japan \\ (Received April 2, 2020 and accepted May 27, 2020)
}

\begin{abstract}
The longitudinal sound absorption capability and air permeability of three species of Japanese wood were investigated. The air permeability values of Sugi, Chanchin-modoki, and Yurinoki were 0.5, 0.06, and 0 (air flow not detected) darcy for the heartwood and 18.2, 0.92, and 0.91 darcy for the sapwood, respectively. The noise reduction coefficients of those three species were $0.04,0.04$, and 0.09 for the heartwood and 0.11 , 0.05 , and 0.14 for the sapwood, respectively. The mean sound absorption coefficients of those sample specimens in the frequency range of $50-6400 \mathrm{~Hz}$ were $0.08,0.06$, and 0.20 for the heartwood and $0.16,0.09$, and 0.30 for the sapwood, respectively. The sound absorption capability of the sample specimens increased with increase in air permeability.
\end{abstract}

Key words: Air permeability, Sound absorption coefficient, Sugi, Chanchin-modoki, Yurinoki

\section{INTRODUCTION}

Wood is a porous material with numerous longitudinal cylindrical pores, although not all species are highly permeable. The permeability variations among wood species are large because the pore structures of woods are very different. Permeability of wood is a topic of interest for many wood researchers because it affects the wood's chemical treatability and drying characteristics. Chemical treatments of wood, such as with preservation chemicals or fire-retardant resin, are generally recognized to increase its permeability. Many researchers have reported the relationship between permeability and drying characteristics (Kanagawa et al., 1992; Hayashi et al., 1995; Lee and Luo, 2002; Lee et al., 2004). Jang and kang (2019) investigated content of three pore types (through pore, blind pore, and closed pore), as defined by IUPAC, and gas permeability of yellow poplar and Korean red pine wood and reported the increasing of through pore content and air permeability in longitudinal direction by heat treatment.

Only a few studies have investigated the relationship between air permeability and sound absorption capability of wood on the surface of a cross-section. Kang et al. (2010, 2012) reported that steam explosion treatment improved wood permeability in the longitudinal direction; in addition, the sound absorption capability of a cross-sectional surface of Yurinoki wood increased compared with the control wood. However, the available

1 Department of Housing Environmental Design, and Research Institute of Human Ecology, College of Human Ecology, Jeonbuk National University, Jeonju 54896, Korea

2 Department of Forest Products, College of Agriculture \& Life Sciences, Chungnam National University, Daejeon 34134, Korea

Laboratory of Wood Science, Department of Forest and Forest Product Science, Faculty of Agriculture, Kyushu University, Fukuoka 812-8581, Japan

* Corresponding author: Sang-Sik JANG (E-mail: ssjang@cnu. ac.kr) information on the relationship between sound absorption properties and permeability of wood is insufficient. In this study, the sound absorption capability and air permeability of several Japanese wood species were investigated. Based on these results, the relationship between air permeability and sound absorption capability on a cross-sectional surface of wood are discussed.

\section{MATERIALS AND METHODS}

\section{Specimen Preparation}

Three kinds of Japanese wood were investigated: Sugi (Cryptomeria japonica), Chanchin-modoki (Choerospondias axillaris), and Yurinoki (Liriodendron tulipifera). Wood specimens $28.9 \mathrm{~mm}$ in diameter and $10 \mathrm{~mm}$ length were dried at room temperature. Five sample specimens of sapwood and heartwood from each of the 3 species were used for estimation of sound absorption coefficient and air permeability in the longitudinal direction (Figure 1).

\section{Gas Permeability Measurement}

Permeability of the specimens was measured with a capillary flow porometer (Porous Material Inc, Model : CFP-1200AEL) using the method described in ASTM 316-03.

Air pressure was applied in the vertical direction to the dried sample. The flow rate was measured, and a graph of flow versus pressure was generated. The relationship between air pressure and permeability is shown in equation [1]:

$$
V=-\left(\frac{k}{\mu}\right) \cdot \frac{d P}{d x}
$$

where

$$
\begin{aligned}
& \mathrm{v}=\text { linear flow rate } \\
& \mathrm{k}=\text { specific or simple permeability }
\end{aligned}
$$


$\mu=$ viscosity of the fluid

$\mathrm{P}=$ pressure

$\mathrm{x}=$ displacement in the direction of flow

\section{Sound Absorption Coefficient Measurement}

The sound absorption rate of each specimen was measured by a two-microphone transfer function method using an impedance tube (B\&K Company, kit type 4706), pulse analysis equipment, and a spectrum analyzer (B\&K company), as described previously (Kang et al., 2012). When sound absorption rate was measured, the diameter of the impedance tube was limited by frequency. Generally, the diameter was $29 \mathrm{~mm}$ for the high-frequency range and $99 \mathrm{~mm}$ for the low-frequency
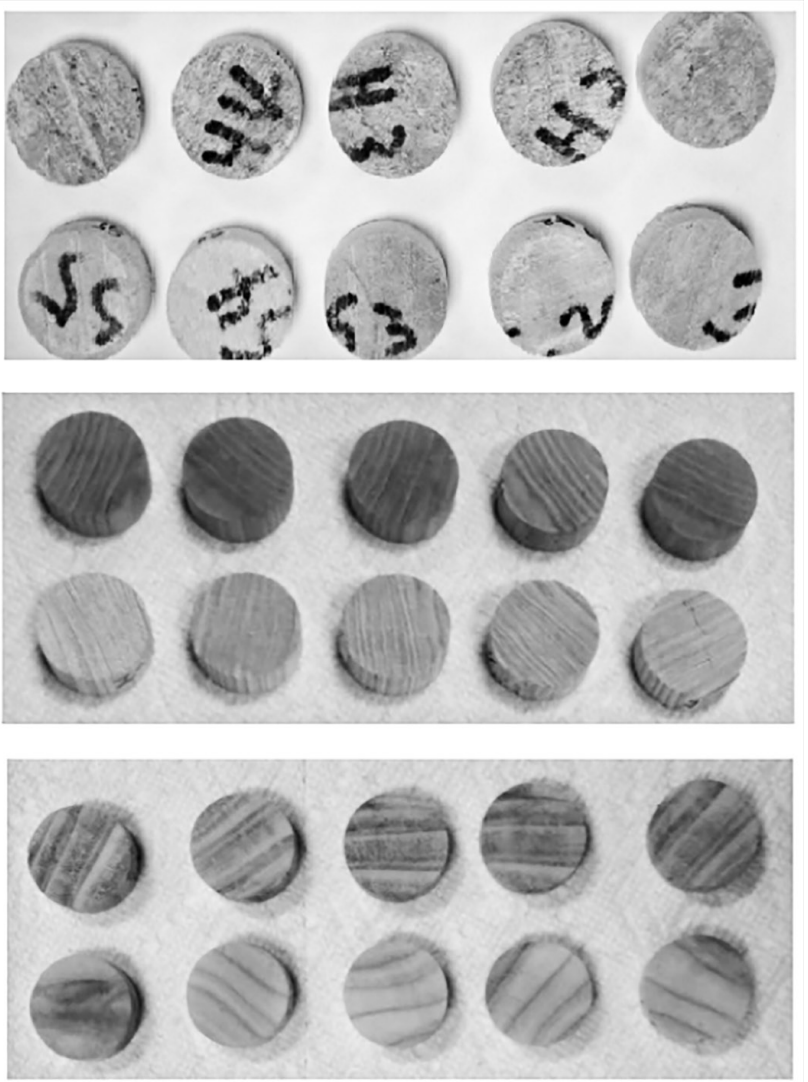

Fig. 1. Sample specimens.

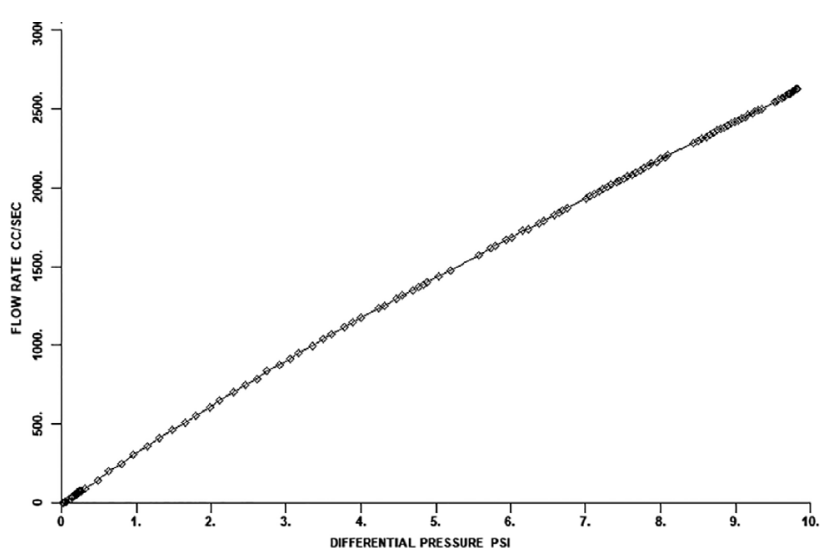

Fig. 2. Typical results of gas permeability obtained using a filtration medium (Jena and Gupta. 2002). range. In this study, variations in sound absorption rate were measured as a change of frequency in the range of $500 \mathrm{~Hz}$ to $6400 \mathrm{~Hz}$ using an impedance tube with a diameter of $29 \mathrm{~mm}$. The temperature, relative humidity, atmospheric pressure, velocity of sound, air density, and acoustic impedance were measured to be $26.30^{\circ} \mathrm{C}$, $57.00 \%, \quad 1013.25 \mathrm{hP}, \quad 346.91 \mathrm{~m} / \mathrm{s}, \quad 1.177 \mathrm{~kg} / \mathrm{m}^{3}$, and 408.20 Pa/(m/s), respectively.
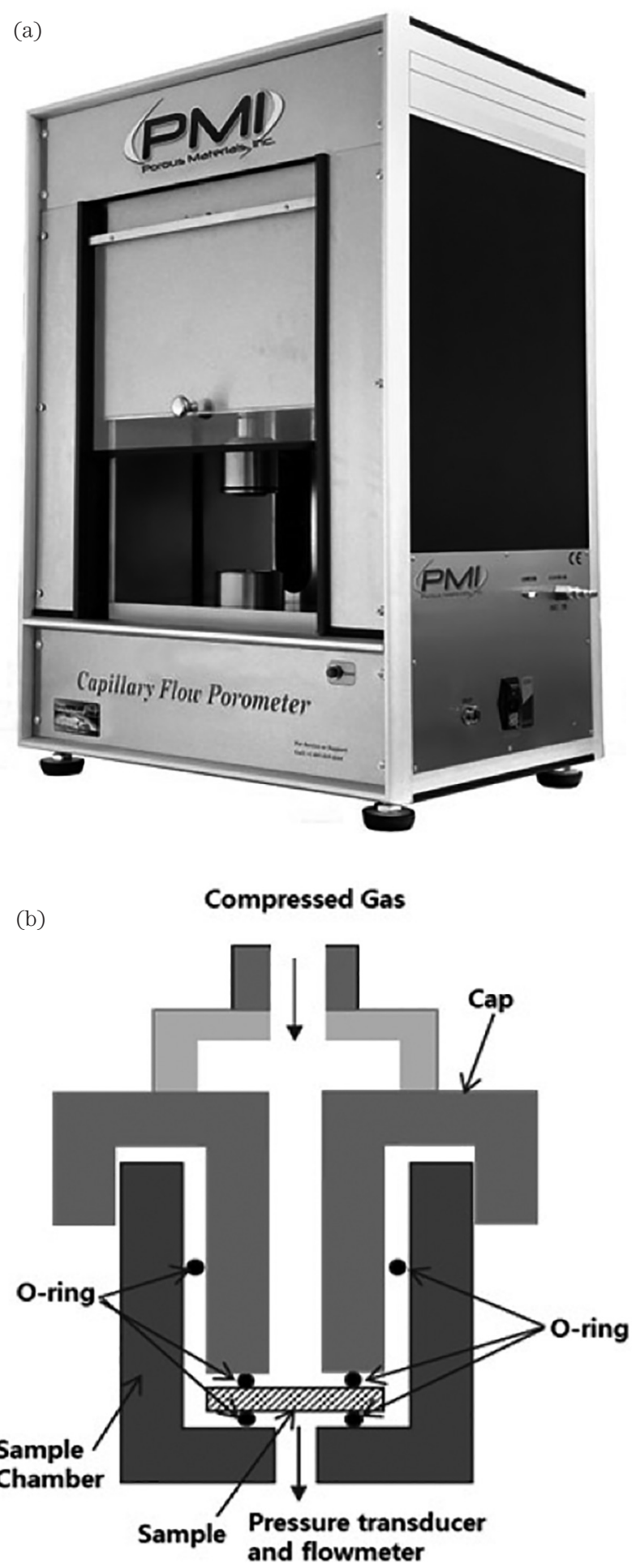

Fig. 3. Permeability estimation equipment: (a) CFP-1200AEL and (b) sample chamber. 


\section{RESULTS AND DISCUSSION}

\section{Permeability}

The permeabilities of the sapwood and heartwood specimens for the 3 species are presented in Figures 5-7. The average permeabilities of Sugi heartwood, Sugi sapwood, Chanchin-modoki heartwood, Chanchinmodoki sapwood, Yurinoki heartwood, and Yurinoki sapwood were $0.5,18.2,0.06,0.92,0$ (air flow not detected), and 0.91 darcy, respectively. The air permeability of the Yurinoki sapwood specimens was 18.2 darcy, which is more than 36 times higher than that of the

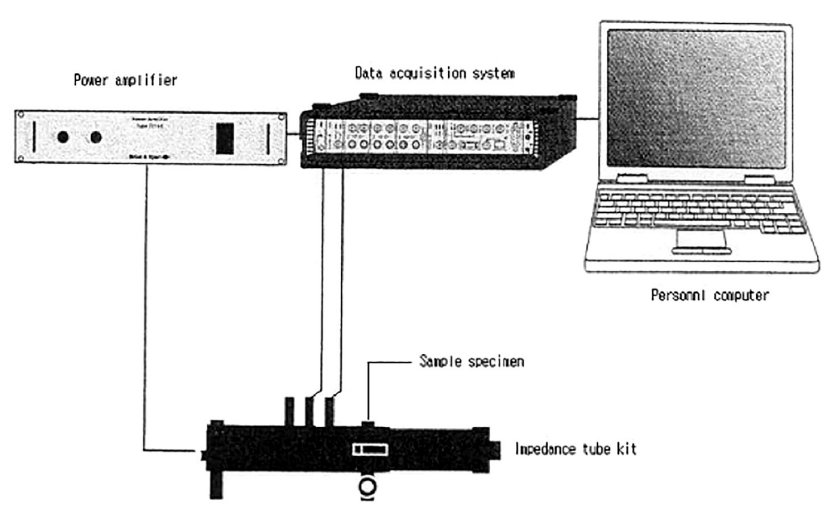

Fig. 4. Sound absorption estimation equipment.

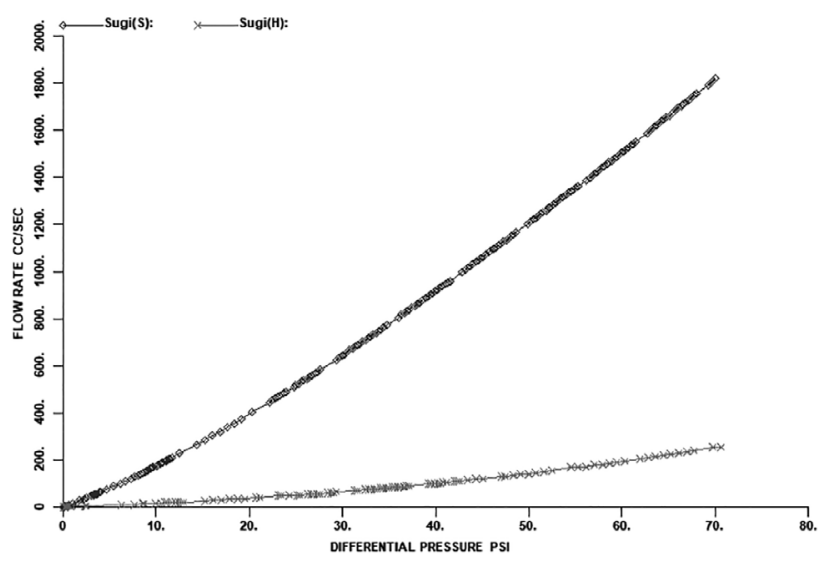

Fig. 5. Gas permeability of Sugi heartwood (H) and sapwood (S).

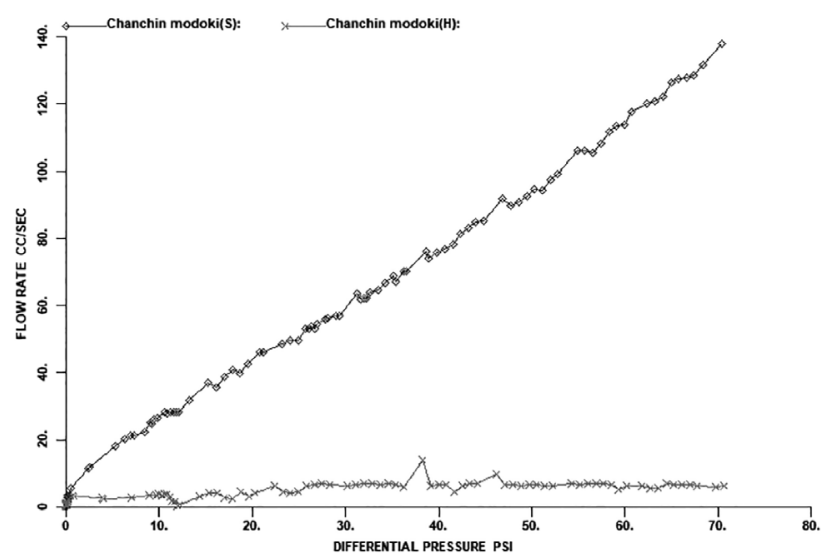

Fig. 6. Gas permeability of Chanchin-modoki heartwood $(\mathrm{H})$ and sapwood (S). heartwood specimens (0.5 darcy).

The pore size of Chanchin-modoki sapwood was the largest among the three species; however, its permeability was less than that of Yurinoki, which might be attributed to presence of tylosis blocking the passageway for fluid movement. The permeability was highest for Yurinoki and lowest for Chanchin-modoki, and it was higher in sapwood than in heartwood.

\section{Sound absorption coefficients}

The sound absorption coefficients of the specimens in the frequency range of $500-6400 \mathrm{~Hz}$ are shown in Figures 8-13.

As shown in the figures, the sound absorption rate of the specimens was highest for Yurinoki and lowest for Chanchin-modoki. The coefficients was also higher in sapwood than in heartwood; in particular, it was almost two times higher in sapwood than in heartwood for Yurinoki in the frequency range of 1500-2000 Hz.

As shown in the figures, the sound absorption coefficients of the highly permeable Yurinoki sapwood specimens had higher values than those of Yurinoki heartwood or the other species of wood in almost all frequency ranges. The sound absorption coefficients of all estimated wood specimens increased with increase in frequency, which is a typical characteristic of a porous sound absorber.

The noise reduction coefficients of Sugi heartwood, Sugi sapwood, Chanchin-modoki heartwood, Chanchinmodoki sapwood, Yurinoki heartwood, and Yurinoki sapwood were $0.04,0.11,0.04,0.05,0.09$, and 0.14 , respectively. In addition, the mean sound absorption rates of Sugi heartwood, Sugi sapwood, Chanchin-modoki heartwood, Chanchin-modoki sapwood, Yurinoki heartwood, and Yurinoki sapwood were 0.08, 0.16, 0.06, 0.09, 0.20 and 0.30 , respectively.

Based on our results, it can be concluded that the sound absorption coefficients of highly permeable wood specimens are greater than those of less permeable wood specimens because the increased air flow assists with sound wave attenuation.

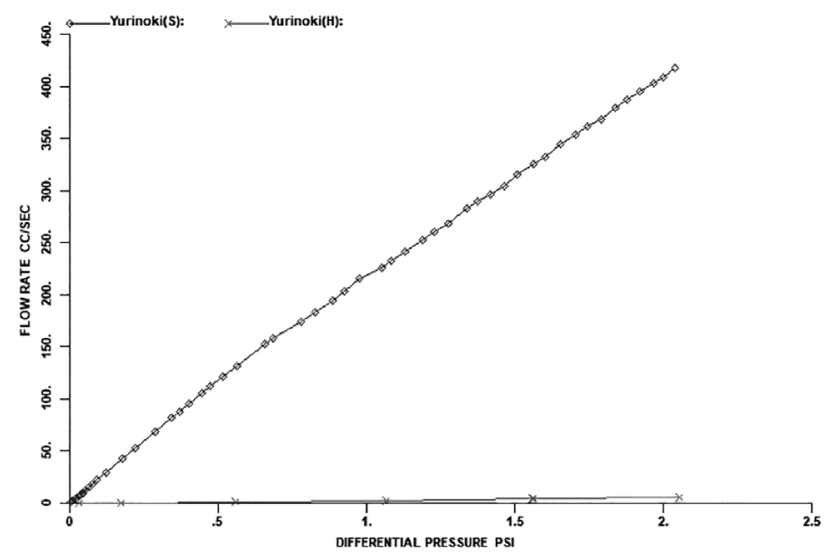

Fig. 7. Gas permeability of Yurinoki heartwood $(\mathrm{H})$ and sapwood (S). 


\section{CONCLUSIONS}

To determine the relationship between sound absorption coefficients and permeability, the sound absorption coefficients and permeability of several wood specimens were measured in this study. The results of this study were as follows:

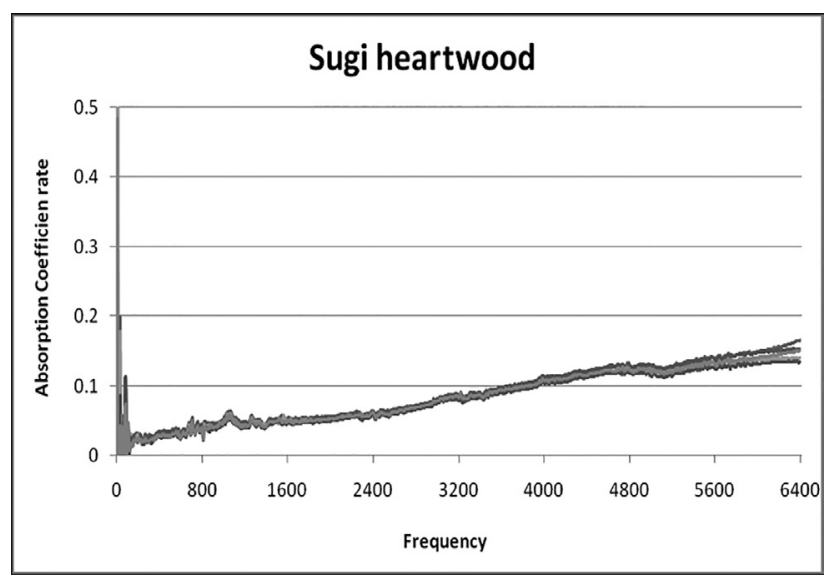

Fig. 8. Frequency versus sound absorption coefficients of heartwood $(\mathrm{H})$.

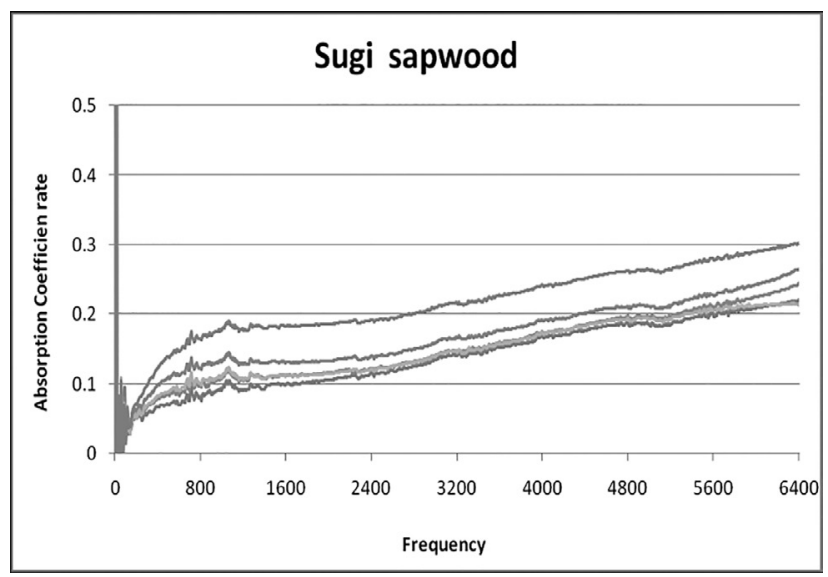

Fig. 9. Frequency versus sound absorption coefficients of sapwood (S).

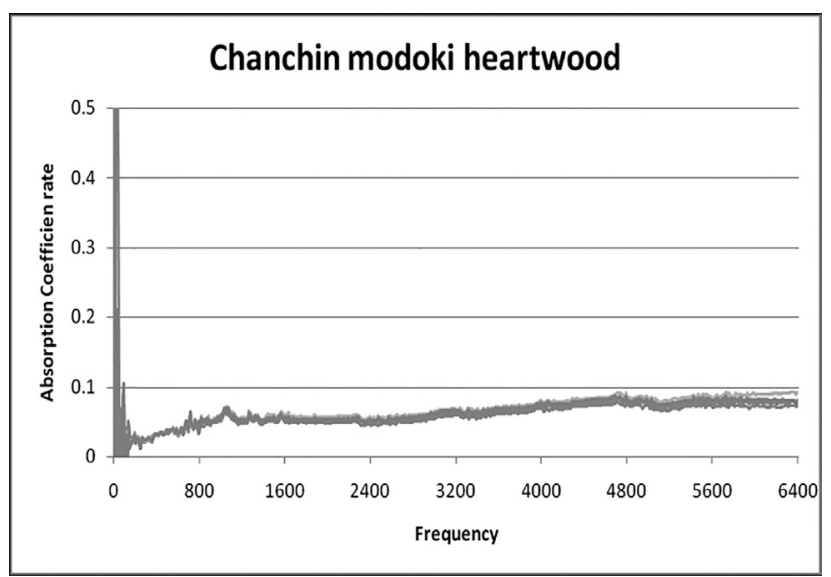

Fig. 10. Frequency versus sound absorption coefficients of Chanchin-modoki heartwood (H).
1. The sound absorption coefficients was highest for the highly permeable wood specimens in almost all frequency ranges.

2. The air permeability of sapwood was greater than that of heartwood, as estimated by capillary flow porometer.

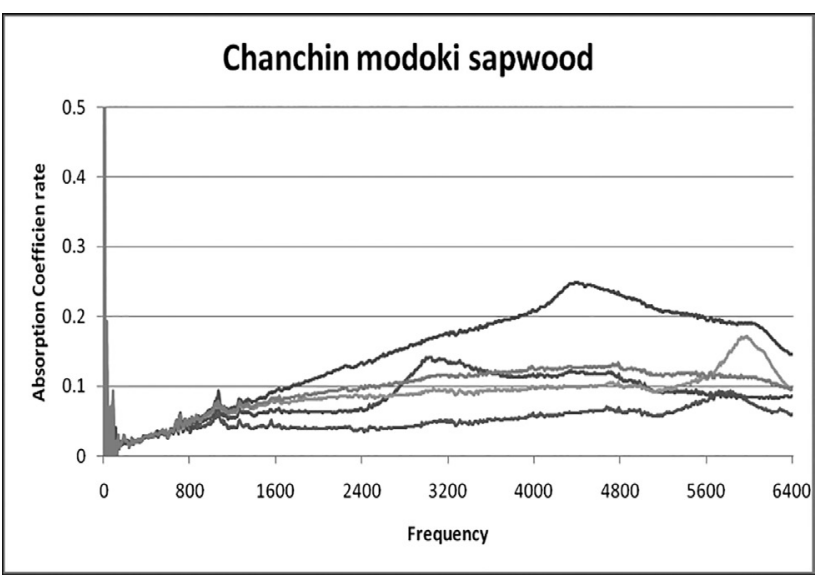

Fig. 11. Frequency versus sound absorption coefficients of Chanchin-modoki sapwood (S)

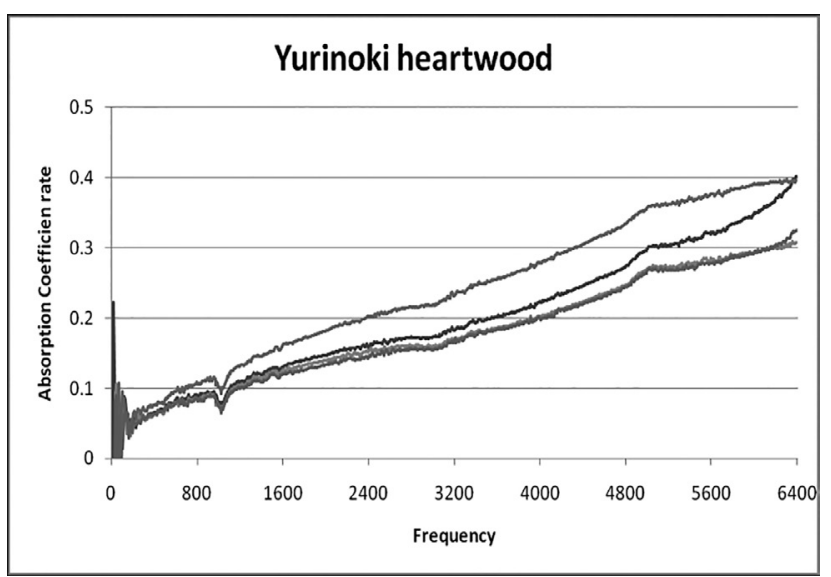

Fig. 12. Frequency versus sound absorption coefficients of Yurinoki heartwood $\mathrm{H}$ ).

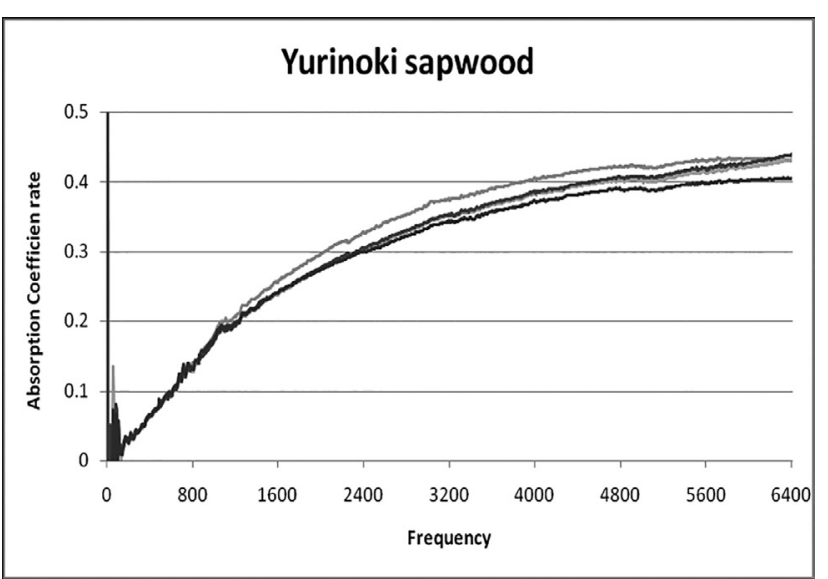

Fig. 13. Frequency versus sound absorption coefficients of Yurinoki sapwood (S) 


\section{ACKNOWLEDGMENTS}

This research was supported by the Basic Science Research Program through the National Research Foundation of Korea (NRF) funded by the Ministry of Science and ICT (NRF-2019R1I1A3A02059471).

\section{AUTHORS' CONTRIBUTIONS}

C. W. Kang designed the study, performed the experiments and wrote the paper. E. S. Jang, S. S. Jang, M. Hasegawa and J. Matsumura provided important comment. All authors assisted in editing of the manuscript and approved the final version.

\section{REFERENCES}

Akshaya Jena and Krishna Gupta. 2002 Characterization of Pore Structure of Filtration Media. Fluid/particle Separation Journal. 14(3): 227-241

Hayashi K., Nakamura K., Kanagawa Y., Yasuzima M., Aoki K. 1995
Improvement of dryability of wood and its distribution by local steam explosion (in Japanese). J. Soc. Material Science $\mathbf{4 4}$ 279-283

Kanagawa Y, Hayashi K, Yasuzima M., 1992 Improvement of dryability by local steam explosion for japanese cedar. Proceedings of the 3rd IUFRO wood drying conference 269-276

Kang C-W, Oh S-W, Lee T-B, Kang W, Matsumura J (2012) Sound absorption capability and mechanical properties of a composite rice hull and sawdust board. $J$ Wood Sci 8:273-278

Kang, C-W, Kim G-C, Park H-J, Lee N-H, Kang W, Matsumura J (2010) Changes in permeability and sound absorption capability of yellow poplar wood by steam explosion treatment. $J$ Fac Agr Kyushu Univ 55(2): 327-332

Jang, E.-S. and Kang, C.-W. (2019a) Changes in gas permeability and pore structure of wood under heat treating temperature conditions. J Wood Sci 65(37): 1-9

Lee, N. H. and Luo, J. Y. 2002 Effect of steam explosion treatments on drying rates and moisture distributions during radiofrequency/vacuum drying of larch pillar combined with a longitudinal kerf. J. of Wood Science 48(4): 270-276

Lee, N. H. Park, H. J. Li Chengyuan and Jin Y. M. 2004 Effect of low pressure steam explosion treatments on prevention of resin exudation from wood under high temperature surroundings.(in Korean) J. of the Korean Wood Science and Technology 32(2): $9-18$ 
